\title{
DAFS-25k impact on cattle's thyroid hormonal status
}

\author{
Roman Vasilev ${ }^{1 *}$, Irina Vasileva $^{2}$, Natalya Yugatova $^{1}$, and Eugene Troshin ${ }^{1}$ \\ ${ }^{1}$ St. Petersburg State Academy of Veterinary Medicine, St. Petersburg 196084, Russia \\ ${ }^{2}$ Izhevsk State Agricultural Academy, Izhevsk 426069, Udmurt Republic, Russia
}

\begin{abstract}
The paper studies the impact of selenium organic preparation DAFS-25k on thyroid capacity in pregnant cows. A stud farm which the work is done in is a biogeochemical province distinguished by a sharp deficit of selenium and iodine in the diet. DAFS-25k had been implanted into the animals subcutaneously during 1 month 30 days before the predicted calving. A sterile $0.6 \%$ DAFS-25k oil solution was used in doses containing $2 \mathrm{mg} / \mathrm{cow} / \mathrm{day}, 6 \mathrm{mg} / \mathrm{cow} / \mathrm{day}$ and $12 \mathrm{mg} / \mathrm{cow} / \mathrm{day}$. It was found that the cows' diet is deficient in iodine and selenium by 63 and $82 \%$ respectively. Daily use of selenium in DAFS-25k in the dose range causes a decrease in the concentration of free thyroxine due to deiodination activating by selenium dependent deiodinases of the first and second types. Consequently, there is a progressive increase in the blood content of total triiodothyronine in all experimental animals as relating to the background values. In this case, the concentration of thyroid-stimulating hormone decreases in blood serum by the $30^{\text {th }}$ day according to the principle of negative feedback. In control animals, an increase in the serum concentration of thyroid-stimulating hormone reached the point 1.8 by the $30^{\text {th }}$ day, total triiodothyronine increased by 14 and $19 \%$ by the $21^{\text {st }}$ day and the $30^{\text {th }}$ day respectively, while the concentration of free thyroxine was reduced by $19 \%$ by the $30^{\text {th }}$ day. The use of selenium in the setting of iodine deficiency leads to aggravation of iodine deficiency.
\end{abstract}

\section{Introduction}

Selenium refers to a group of seven elements (iron, calcium, magnesium, iodine, selenium, zinc, copper). Their deficiency is an urgent and most common problem in the world [1]. Special biogeochemical situations in many regions of the country, including the Udmurt Republic (mainly due to deficiency of selenium and iodine) provokes various adaptive and disadaptive shifts realized through hormonal mechanisms and thyroid secretion.

The iodine content in the main components of the agricultural landscapes of Udmurtia is low. This fact is confirmed by endemic pathologies in humans and animals, which is associated with impaired thyroid function. Republic continentally causes a deficiency of selenium along with a lack of iodine. Regions with the soil containing less than $50 \mathrm{mcg} / \mathrm{kg}$ selenium are considered endemic. In the biosphere, selenium migration occurs along the food chain: soil selenium plant selenium - animal selenium - human selenium.

Thus, the soil determines the main role in the formation of selenium status of all territories. According to the Institute of Nutrition, Russian Academy of Medical Sciences, the daily diet of the population of the republic is 1.5-2.0 times lower than the physiological needs of the body. The selenium deficiency is associated with a number of factors [2].

As early as in the middle of the 20th century, selenium antioxidant properties were established and it was determined as an essential microelement for humans and animals. Its key functions are hydroperoxides and lipid peroxides destruction as well as protection from oxidative stress [3]. Selenium prevents the destruction of thyroid tissue, eliminating the accumulation of hydrogen peroxide in thyroid, participates in the metabolism of its hormones and has oncoprotective potential $[4,5]$.

It was shown in animal experiments that combined deficiency of selenium and iodine leads to more pronounced hypothyroidism than the deficiency of iodine only. Thyroid is the organ with the highest selenium content per 1 gram of the tissue, since it expresses specific selenium-containing proteins [6]. Apart from the role of selenium in a thyroid hormones metabolism, its effect on the hormonal organ volume has also been studied. It has been established that taking iodine preparations alone does not reduce the volume of goiter and does not improve thyroid function in regions where iodine and selenium deficiency is observed. It was established that, the more obvious the deficiency of selenium is, the less influence the iodine preparations have on the thyroid volume [7,8].

The thyroid hormones imbalance is a distinguishing characteristic of goitrous endemy arising from the combination of low values of iodine and selenium. This imbalance is manifested by the accumulation of thyroxine with a parallel decrease in the value of triiodothyronine, which leads to the development of dysteriosis symptoms. Lack of selenium aggravates the iodine deficiency manifestation causing thyroid

* Corresponding author: veterenar4ik@mail.ru 
dysfunction, inducing necrotic and fibrinous changes in thyroid and stimulating cell proliferation. One of the reasons why endemic goiter in iodine-deficient regions is impossible to eliminate completely is that selenium deficit causes a decrease in the synthesis of enzymes involved in activation and regulation of a thyroid hormones balance and adding iodine does not compensate for this defect $[9,10]$.

Chronic deficiency of a number of microelements in animal nutrition cannot be repleted by a short introduction into diets and leads to the violation of other microelements content in the blood. Over the years, researchers from different countries have confirmed that lack of selenium and iodine in the diet of farm animals leads to impaired reproductive function with a change in the ovarian cycle, infertility, emergence and development of acute and chronic endometritis, late arrival in sexual heat and birth of non-viable young animals, which certainly is an objective basis for the study of pathological conditions caused by the lack of these trace elements in order to study the pathogenesis of animals' endocrinous status and finding effective therapeutic drugs [7, 11].

Organic selenium preparations have a positive effect on the exterior of fattening bulls as well as an increase in average daily gain in live weight. It is reported that the preparation has a positive effect on ovaries structure and generally has a positive effect on reproductive function in a general and clinical status of animals. In this regard, studying the role of drugs containing trace elements on the structure and function of thyroid is of great interest $[12,13]$.

\section{Materials and research methods}

The study was carried out on the basis of a black-andwhite cattle breeding plant Agricultural production cooperative-collective farm "Luch", Udmurt Republic, Vavozhsky District. The experiment was performed on 24 cows, black-and-white breed with live weight of $535.4 \pm 25.0 \mathrm{~kg}$ in the dry period 1 month before calving. The organo-selenium preparation DAFS-25k (Sulfat LLC, Russia, Saratov), which contains $25 \%$ diacetophenonyl selenide as the active substance was used to carry out the experiment. The preparation was implanted subcutaneously once a day in the form of a sterile $0.6 \%$ oil solution, $1 \mathrm{ml}$ of which contained $12 \mathrm{mg}$ of diacetophenonyl selenide, which, in terms of selenium, was $3 \mathrm{mg} / \mathrm{ml}$.

4 groups of experimental animals were formed according to the principle of analogues. There were 6 cows in each group. $2 \mathrm{ml}$ of a $0.6 \%$ DAFS-25k oil solution was implanted hypodermically in the middle third of the neck in the first experimental group thirty days before calving, which, in terms of selenium, was 3 $\mathrm{mg}$ once a day with an interval of 24 hours within 30 days.

$4 \mathrm{ml}$ of $0.6 \%$ DAFS-25k oil solution was implanted hypodermically in the middle third of the neck in the second experimental group thirty days before calving, which in terms of selenium was $6 \mathrm{mg}$ once a day with an interval of 24 hours for 30 days.

$8 \mathrm{ml}$ of $0.6 \%$ DAFS-25k oil solution was implanted hypodermically in the middle third of the neck in the third experimental group, which in terms of selenium was $12 \mathrm{mg}$ once a day with an interval of 24 hours within 30 days.

$8 \mathrm{ml}$ of sterile vegetable oil was implanted hypodermically in the middle third of the neck in the fourth group being control animals 30 days before calving once a day with an interval of 24 hours for 30 days.

Blood samples were taken for hematological studies from the caudal vein in vacutainers containing Plot activator with the objective to obtain blood serum. Blood was taken 1 hour before the first injection of drugs as well as 7 days, 14 days, 21 days and 30 days after the experiment started. Whole blood tubes were centrifuged at $3000 \mathrm{rpm}$ during 10 minutes.

The concentration of thyroid-stimulating hormone (TSH), $\mu \mathrm{IU} / \mathrm{ml}$, total triiodothyronine (vol.T3), $\mathrm{nmol} / \mathrm{L}$ and free thyroxine (St. T4), nmol/l was determined in the obtained blood serum with the application of enzymelinked immunosorbent assay (ELISA). For EIA, readymade kits manufactured by the AlkorBio group of companies (Russia, St. Petersburg) were used.

Animals were observed clinically, which included assessment of the general condition, feed intake, assessment of the coat, visible mucous membranes.

The data obtained were subjected to statistical processing using the program Statistica10. Results were evaluated using the Wilcoxon sign test and the MannWhitney $U$ test. The differences were considered significant at $\mathrm{p}<0.05$. Data are presented as median (M) and quartile range from 25 to $75 \%$ ([Q25; Q75]).

\section{Research results}

When analyzing the diet of dry cows during winter (Table 1), it was found that it is balanced in terms of basic nutrients, calcium and phosphorus. However, manganese excess was found to be $16 \%$, iron excess is equal to $169 \%$; deficiency of cobalt, zinc and copper are, respectively, $7 \%, 34 \%$ and $40 \%$, Vitamin A deficiency is $73 \%$, Vitamin D is $76 \%$, Vitamin $\mathrm{E}$ is $98 \%$. Deficiency of iodine and selenium was $63 \%$ (5.06 mg) and selenium $82 \%$ (4.9 mg).

Table 1. Daily ration of dry cows during winter (stall period) in Agricultural production cooperative-collective farm "Luch"

\begin{tabular}{|c|c|}
\hline Feeding & Amount per day, kg \\
\hline Grass-and-legume hay & 5.0 \\
\hline Legume-grass ensilage & 15.0 \\
\hline Concentrated food & 3.0 \\
\hline Sunflower meal & 0.6 \\
\hline Molasses & 1.5 \\
\hline Starch-derived sugar & 0.3 \\
\hline Feeding chalk & 0.071 \\
\hline Monocalcium phosphate & 0.13 \\
\hline Sodium chloride & 0.1 \\
\hline
\end{tabular}


According to veterinarians' reports, insufficient content of iodine and selenium in a diet implies high incidence of white muscle disease and endemic goiter among calves.

During the research, the experimental and control animals were subjected to daily clinical observation. As a resut, deviations in the animal's health condition were not detected, symptoms of acute and chronic selenium poisoning were not noted.

The concentration dynamics of thyroid-stimulating hormone, total triiodothyronine and free thyroxine in cows of the first group treated with $3 \mathrm{mg}$ of selenium daily are shown in Table 2.

Table 2. Dynamics of thyroid hormones and TSH concentration in blood serum of cows treated with $3 \mathrm{mg}$ of selenium daily, $\mathrm{n}=6, \mathrm{M}$ [Q25; Q75]

\begin{tabular}{|c|c|c|c|c|c|}
\hline Indicator & Background & $7^{\text {th }}$ day & $14^{\text {th }}$ day & $21^{\text {th }}$ day & $30^{\text {th }}$ day \\
\hline TSH, & 0.100 & $0.150 *$ & 0.095 & 0.090 & $0.100 \#$ \\
$\mu \mathrm{me} / \mathrm{ml}$ & {$[0.075 ;$} & {$[0.115 ;$} & {$[0.078 ;$} & {$[0.063 ;$} & {$[0.093 ;$} \\
& $0.113]$ & $0.165]$ & $0.145]$ & $0.105]$ & $0.113]$ \\
\hline vol.T 3, & 4.62 & $5.70 \#$ & $6.18^{*} \#$ & $6.32^{*} \#$ & $6.19 * \#$ \\
nmol / 1 & {$[4.11 ;$} & {$[5.39 ;$} & {$[5.91 ;$} & {$[6.07 ;$} & {$[5.95 ;$} \\
& $5.18]$ & $5.86]$ & $5.41]$ & $6.59]$ & $6.49]$ \\
\hline Free & & & & & \\
thyroxin. & 18.49 & 18.81 & 17.28 & 17.48 & $15.31^{*}$ \\
$\mathrm{~T}_{4}$, & {$[17.72 ;$} & {$[17.41 ;$} & {$[16.51 ;$} & {$[15.67 ;$} & $14.67 ;$ \\
nmol/L & $19.15]$ & $19.08]$ & $17.73]$ & $18.61]$ & $15.50]$ \\
\hline
\end{tabular}

Note: $*$ - the significance of differences according to the Wilcoxon criterion is $<0.05$;

\# - the significance of differences according to the MannWhitney criterion relative to the values in control animals is $<0.05$ (Table 5).

According to table 2, the concentration of TSH significantly increased by the $7^{\text {th }}$ day by $50 \%(\mathrm{p}<0.05)$ with a subsequent decrease by the $30^{\text {th }}$ day to background values. The triiodothyronine total concentration increased during all observation periods from 34 to $37 \%(\mathrm{p}<0.05)$ from the $14^{\text {th }}$ day to the $30^{\text {th }}$ day. A tendency towards the increase in free thyroxine followed by a decrease by $30 \%$ to a level below the background value by $17 \%(\mathrm{p}<0.05)$ was noted by the $7^{\text {th }}$ day.

The dynamics of thyroid-stimulating hormone, total triiodothyronine and free thyroxine concentration in cows of the second group treated with $6 \mathrm{mg}$ of selenium daily are presented in Table 3 .

According to table 3, a progressive increase in the concentration of total triiodothyronine by $23 \%(\mathrm{p}<0.05)$ was observed at all observation periods by the $7^{\text {th }}$ day, by $26 \%(\mathrm{p}<0.05)$ by the $14^{\text {th }}$ day, and by $35 \%(\mathrm{p}<0.05)$ by the $21^{\text {st }}$ day and the $30^{\text {th }}$ day. The dynamics of free thyroxine concentration in the cows' blood serum indicated another situation characterized by a tendency to decrease by the $7^{\text {th }}$ day and a significant decrease from 20 to $24 \%$ from the $14^{\text {th }}$ day to the $30^{\text {th }}$ day ( $\mathrm{p}<0.05$ ). The peak increase in thyroid-stimulating hormone concentration occurred on the $7^{\text {th }}$ day by 1.6 times $(\mathrm{p}<0.05)$ and was followed by a decrease to the values slightly different from the background ones.

The dynamics of thyroid-stimulating hormone, total triiodothyronine and free thyroxine concentration in the cows of the second group treated with $12 \mathrm{mg}$ of selenium daily are shown in Table 4.

Table 3. Dynamics of thyroid hormones and TSH concentration in blood serum of cows treated with $6 \mathrm{mg}$ of selenium daily, $\mathrm{n}=6$, M [Q25; Q75]

\begin{tabular}{|c|c|c|c|c|c|}
\hline Indicator & Background & $7^{\text {th }}$ day & $14^{\text {th }}$ day & $21^{\text {th }}$ day & $30^{\text {th }}$ day \\
\hline TSH, & & $0.155^{*}$ & 0.130 & 0.115 & $0.110 \#$ \\
$\mu \mathrm{me} / \mathrm{ml}$ & 0.095 & {$[0.115 ;$} & {$[0.110 ;$} & {$[0.098 ; 0$} & {$[0.088 ;$} \\
& {$[0.080 ; 0.148]$} & $0.180]$ & $0.158]$ & $.125]$ & $0.123]$ \\
\hline vol.T $_{3}$ & 4.65 & $5.73^{* \#}$ & $5.86^{* \#}$ & $6.26^{* \#}$ & $6.27^{*} \#$ \\
nmol / & {$[4.36 ;$} & {$[5.35 ;$} & {$[5.61 ;$} & {$[6.13 ;$} & {$[6.12 ;$} \\
& $5.08]$ & $5.94]$ & $6.03]$ & $6.51]$ & $6.48]$ \\
\hline Free & & & & & \\
thyroxin & 21.05 & 19.35 & $16.75^{*}$ & $16.05^{*}$ & $16.80^{*}$ \\
. $\mathrm{~T}_{4}$, & {$[18.20 ;$} & {$[16.20 ;$} & {$[14.43 ;$} & {$[15.10 ;$} & {$[15.13 ;$} \\
nmol$/ \mathrm{L}^{2}$ & $23.08]$ & $20.20]$ & $18.23]$ & $18.00]$ & $18.63]$ \\
\hline
\end{tabular}

Note: * - the significance of differences according to the Wilcoxon criterion is $<0.05$;

\# - the significance of differences according to the Mann-

Whitney criterion relative to the values in control animals is $<0.05$ (Table 5).

Table 4. Dynamics of thyroid hormones and TSH concentration in blood serum of cows treated with $12 \mathrm{mg}$ of selenium daily, $n=6, M$ [Q25; Q75]

\begin{tabular}{|c|c|c|c|c|c|}
\hline Indicator & Background & $7^{\text {th }}$ day & $14^{\text {th }}$ day & $21^{\text {th }}$ day & $30^{\text {th }}$ day \\
\hline TSH, & 0.060 & 0.085 & $0.100 \#$ & 0.080 & $0.075 \#$ \\
$\mu \mathrm{me} / \mathrm{ml}$ & {$[0.050 ;$} & {$[0.060 ;$} & {$[0.063 ;$} & {$[0.012 ;$} & {$[0.060 ;$} \\
& $0.070]$ & $0.113]$ & $0.120]$ & $0.105]$ & $0.093]$ \\
\hline vol.T 3, & 4.55 & $5.79^{*} \#$ & $6.10^{* \#}$ & $6.67^{* \#}$ & $6.36^{* \#}$ \\
nmol $/ 1$ & {$[4.36 ;$} & {$[5.35 ;$} & {$[5.94 ;$} & {$[6.21 ;$} & {$[6.20 ;$} \\
& $4.66]$ & $6.07]$ & $6.27]$ & $6.99]$ & $6.60]$ \\
\hline Free & 20.70 & 19.05 & $16.05^{*}$ & $15.95^{*}$ & $14.45^{*}$ \\
thyroxin. $\mathrm{T}_{4}$, & {$[19.10 ;$} & {$[18.05 ;$} & {$[14.8 ;$} & {$[14.78 ;$} & {$[13.63 ;$} \\
nmol/L & $21.17]$ & $20.20]$ & $17.18]$ & $18.00]$ & $15.48]$ \\
\hline
\end{tabular}

Note: $*$ - the significance of differences according to the Wilcoxon criterion is $<0.05$;

\# - the significance of differences according to the MannWhitney criterion relative to the values in control animals is $<0.05$ (Table 5).

According to table 4, there were no significant changes in the dynamics of thyroid-stimulating hormone concentration at all observation periods. However, there was a tendency to increase it up to 30 days. The triiodothyronine total concentration progressively increased by $27 \%$ (p <0.05), $34 \%$ (p <0.05), $47 \%$ $(\mathrm{p}<0.05)$ and $40 \%(\mathrm{p}<0.05)$, by the $7^{\text {th }}$ day, the $14^{\text {th }}$ day, the $21^{\text {st }}$ day and the $30^{\text {th }}$ day respectively. The free thyroxine serum concentration significantly decreased from the $14^{\text {th }}$ day to the $30^{\text {th }}$ day by $22 \%$ (p <0.05), $23 \%(\mathrm{p}<0.05)$ and $30 \%(\mathrm{p}<0.05)$ respectively.

Table 5 presents the dynamics of thyroid-stimulating hormone and thyroid hormones concentrations in the blood serum of the control group cows, which were implanted with sterile vegetable oil.

According to the data presented in Table 5, the tendency to serum concentration of thyroid-stimulating hormone increase by the $30^{\text {th }}$ day was statistically significant at $1.8(\mathrm{p}<0.05)$ and total triiodothyronine by the $21^{\text {st }}$ day and the $30^{\text {th }}$ day by $14 \%(\mathrm{p}<0.05)$ and $19 \%$ ( $p<0.05$ ), respectively, against the background of a $19 \%$ $(p<0.05)$ decrease in free thyroxine concentration by the $30^{\text {th }}$ day. 
Table 5. Dynamics of thyroid hormones and TSH concentration in blood serum of the control group cows receiving daily sterile vegetable oil, $\mathrm{n}=6, \mathrm{M}$ [Q25; Q75]

\begin{tabular}{|c|c|c|c|c|c|}
\hline Indicator & Background & $7^{\text {th }}$ day & $14^{\text {th }}$ day & $21^{\text {th }}$ day & $30^{\text {th }}$ day \\
\hline TSH, & 0.095 & 0.105 & 0.135 & 0.100 & $0.170^{*}$ \\
$\mu \mathrm{me} /$ & {$[0.085 ;$} & {$[0.088 ;$} & {$[0.120 ;$} & {$[0.071 ;$} & {$[0.163 ;$} \\
$\mathrm{ml}$ & $0.125]$ & $0.138]$ & $0.145]$ & $0.123]$ & $0.175]$ \\
\hline vol.T $_{3}$, & 4.42 & 4.58 & 4.66 & $5.04^{*}$ & $5.25^{*}$ \\
nmol/l & {$[4.25 ;$} & {$[4.45 ;$} & {$[4.56 ;$} & {$[4.94 ;$} & {$[5.14 ;$} \\
& $4.85]$ & $5.00]$ & $4.92]$ & $5.22]$ & $5.47]$ \\
\hline Free & & & & & \\
thyroxi & 18.73 & 18.80 & 17.32 & 15.63 & $15.09^{*}$ \\
n.T 4 & {$[16.93 ;$} & {$[16.10 ;$} & {$[16.87 ;$} & {$[15.25 ;$} & {$[14.73 ;$} \\
nmol/L & $19.28]$ & $19.08]$ & $17.63]$ & $16.63]$ & $15.50]$ \\
\hline
\end{tabular}

Note: $*$ - the significance of differences according to the Wilcoxon criterion is $<0.05$

Comparison of the values of thyroid-stimulating hormone concentration indicators in the blood serum of the cows receiving DAFS-25k with the control animals noted a significant decrease in hormone levels by the $30^{\text {th }}$ day in experimental animals of the first, second and third groups by $41 \%$ (p <0.05), $35 \%(\mathrm{p}<0.05)$ and $56 \%$ ( $\mathrm{p}<0.05)$, respectively, relative to control values. By the $14^{\text {th }}$ day, the concentration of thyroid-stimulating hormone in cows receiving $12 \mathrm{mg}$ of selenium in DAFS$25 \mathrm{k}$ was $26 \%$ ( $\mathrm{p}<0.05)$ lower than in the control animals during the same observation period.

A progressive increase was observed in the dynamics of triiodothyronine total concentrations, at all observation periods in all experimental animals receiving selenium subsidies relative to control animals during the same observation periods: in the first experimental group the increase was by $18-33 \%(\mathrm{p}<0.05)$; in the second experimental group by $19-26 \%(\mathrm{p}<0.05)$; in the third experimental group it was by $21-32 \%$ ( $\mathrm{p}<0.05)$.

Significant differences in the content of free thyroxine in the blood serum of animals treated with selenium in DAFS-25k and control cows were not found.

\section{Discussion}

The endemicity for selenium and iodine deficiency [2] of the region, in which the experiment was carried out, has been confirmed by an analysis of the animals diet as well as development of the diseases caused by chronic selenium deficiency in livestock of different sex and age groups, such as white muscle disease, endemic goiter, according to the reports of the veterinary specialists of Agricultural production cooperative-collective farm "Luch". Selenium-dependent deiodinase of the third type catalyzes inactivation of thyroxin to the reverse triiodothyronine. Moreover, deiodinase of the third type is predominantly expressed in pregnant animals' placenta and uterus as well as in liver, brain and skin of the fetus. According to experimental study, selenium supplements in the late fetal period of pregnancy, significantly affect the functional activity of mother's thyroid, and the quality of the offspring indirectly through the homonous status and directly through the third type deiodinase [14].
Provision of mothers with selenium and iodine determines thyroid status of young cattle.

The published literature data are consistent with the experimental results. Selenium in the composition of DAFS-25k during daily implantation to dry cows for 30 days at a dose of $2 \mathrm{mg} / \mathrm{cow} / \mathrm{day}, 6 \mathrm{mg} / \mathrm{cow} /$ day and $12 \mathrm{mg} / \mathrm{cow} /$ day under conditions of chronic alimentary selenodeficiency and iodine deficiency provokes a decrease in the concentration of free thyroxine by activating the reaction of selenium deiodination with dependent deiodinases of the first and second type [15]. As a result, there is a progressive increase in the blood content of total triiodothyronine in all experimental animals relative to the background values. In this case, concentration of thyroid-stimulating hormone in blood serum decreases by the $30^{\text {th }}$ day according to the principle of negative feedback due to an increase in the level of total triiodothyronine.

Assessment of the thyroid hormone status in pregnant cows not receiving selenium supplements indicates the progression of chronic iodine deficiency, which by the 30th day is demonstrated by a significant increase in the concentration of thyroid-stimulating hormone to 0.170 $[0.163 ; 0.175] \mu \mathrm{IU} / \mathrm{ml}$ relative to the background values of $0.095[0.085 ; 0.125] \mu \mathrm{MU} / \mathrm{ml}$ against the background of a significant increase in the content of total triiodothyronine to $5.22[5.14 ; 5.47] \mathrm{nmol} / \mathrm{L}$ by the 30 th day in contrast to $4.42[4.25 ; 4.85] \mathrm{nmol} / \mathrm{L}$ at the beginning of the experiment.

Long-term thyroid stimulation with elevated levels of thyroid stimulating hormone leads to the increased exposure of hydrogen peroxide, which is an essential compound for the synthesis of thyroid hormones and the development of foci of thyroid necrosis. This process is significantly aggravated by selenium deficiency, at the background of which a decrease in the activity of glutathione peroxidase is noted. Ultimately, endemic myxematous cretinism develops in a fetus $[10,16]$.

\section{Conclusion}

The 30 days daily subcutaneous implantation of pregnant cows with preparation DAFS-25k against a background of severe nutritional deficiency of iodine causes pronounced changes in thyroid functional activity. When subjected to selenium dependent deiodinases of the first and second types, the deiodination of thyroxin is activated and it is transformed into triiodothyronine, which can provoke an increase in iodine deficiency [8].

The combined iodine-alimentary deficiency of the diet of pregnant cows may cause the development of endemic goiter in young animals.

Thus, the management of iodine and selenium deficiency in the elements insufficiently endemic in water, soil, plants and feed should represent a complex of systematic preventive measures, and must start with iodine deficiency elimination. 


\section{References}

1. G.F. Combs, Biomarkers of selenium status, Nutrients, 7 (2015)

2. I.L. Malkova, I.Yu. Rubtsova, Medicalgeographical assessment of the natural conditions of Udmurtia, Monograph (Udmurt University, Izhevsk, 2016)

3. L.H. Duntas, S. Benvenga, Selenium: an element for life, Endocrin., 48(3), 756-775 (2015)

4. M. Hasanuzzaman, M. Hossain, M. Fujita, Selenium in higher plants: physiological role, antioxidant metabolism and abiotic stress tolerance, J. of Plant Sci., 5, 354-375 (2010)

5. E.A. Shabalina, T.B. Morgunova, S.V. Orlova, V.V. Fadeev, Selenium and thyroid, Clin. and experim. thyroidol., 7(2), 7-18 (2011)

6. L.R. Santos, C. Neves, M. Melo, P. Soares, Selenium and selenoproteins in immune mediated thyroid disorders, Diagnostics (Basel), 8(4) (2018)

7. M. Ventura, M. Melo, F. Carrilho, Selenium and thyroid disease: from pathophysiology to treatment, Int. J. Endocrinol., 1297658 (2017)

8. D. Gardner, D. Shoback, Basic \& Clinical Endocrinology, Book 2 (BINOM, Moscow, 2018)

9. J. Kohrle, Pathophysiological relevance of selenium, J. Endocrinol. Invest., 36(10), 1-7 (2013)

10. W. Wang, J. Mao, J. Zhao et al., Decreased thyroid peroxidase antibody titer in response to selenium supplementation in autoimmune thyroiditis and the influence of a SEPP gene polymorphism: a prospective Multicenter study in China, Thyroid (2018)

11. E.A. Troshina, E.S. Senyushkina, M.A. Terekhova, The role of selenium in the pathogenesis of thyroid diseases, Clin. and experim. Thyroidol., 14(4), 192-205 (2018)

12. D.S. Berestov, E.A. Merzlyakova, E.I. Troshin, The antioxidant effect of DAFS-25 in calf fattening and in the prevention of radiation exposure, Veterin. Pathol., 3, 188-192 (2007)

13. M.P. Kuchinsky, Yu.V. Verigo, Influence of a new veterinary preparation based on microelements on the antioxidant status and the state of mineral metabolism in cattle, Actual. issues of veter. Biology, 2(14), 41-48 (2012)

14. A. Drutel, F. Archambeaud, P. Caron, Selenium and the thyroid gland: more good news for clinicians, Clin. Endocrinol. (Oxf), 78(2), 155-164 (2013)

15. A. Harada, E. Nomura, K. Nishimura et al., Type 1 and type 2 iodothyronine deiodinases in the thyroid gland of patients with huge goitrous Hashimoto's thyroiditis, Endocrine (2019)

16. H. Zheng, J. Wei, L. Wang et al., Effects of selenium supplementation on Graves' disease: a systematic review and meta-analysis, Evid. Based Complement Alternat. Med., 3763565 (2018) 